The Portuguese Blood Transfusion System

Gabriel de Olim; Maj/Gen Med. Aeron

Instituto Português de Sangue, IP/Portuguese Blood Institute

The Portuguese Territory is composed of a continental part (mainland) and two archipelagos (Azores and Madeira). The estimated population was 10.6 million, with $<0.5$ million living in the islands (INE-Estimativas Provisórias PR 2008).

The national blood system is anchored in three Regional Blood Centres (CRS) of the Portuguese Blood Institute (IPS) that collects $66.8 \%$ of all donations made in the mainland. The system is regulated by the Competent Authority for Blood and Organ Transplantation and complies with the European Directives, Regulations, and Guidelines on blood and transfusion medicine practice.

Portugal is self-sufficient in blood components ( 40 blood units per 1,000 inhabitants), and all donations are from voluntary, non-remunerated donors. The system is fully certified, highly automated, and transparent to the public.

Almost all of the hospitals are connected to the IPS through a Web-based network system. Orders for blood components are posted online. By using innovative software created in-house, an immediate view of the stock of blood in any hospital, among other relevant information, is immediately available at any time. The access to this software is made through the Internet and the login is restricted to the top managers of each CRS. This tool, very useful for the daily management of blood stocks, also proved to be of great utility in a catastrophe simulation scenario. As it increases readiness, this is a most valuable tool for the management of blood supply in emergencies and natural catastrophic situations in the country. A demonstration will be made during the presentation.

Keywords: blood supply; blood transfusion system; Portugal Prebosp Disast Med 2010;25(5):s103

Underwater and Hyperbaric Naval Medicine (Historical Perspective and Actual Situation)

CFR MN Albuquerque e Sousa

Director, Centre of Underwater and Hyperbaric Medicine

Introduction: In this communication, we emphasize the contribution of the Centre of Underwater and Hyperbaric Medicine (CUHM) for the development of this medical area. Methods: In order to evaluate the performance of the CUHM, its evolution was reviewed and an analysis was conducted of the statistical data related to its activity, from 1989 until December 2008.

Results: The maximum capacity of actuation attained by the CUHM, together with the increase of the Navy's dive activities and with the new definition of its health service politics, implies a structural change of the CUHM in order to expand its activities to allow it to provide the adequate support to the operational underwater activities, to better benefit to the civilian patients, and to increase its investigational activity.

Conclusions: The CUHM activity contributes to the individualization of the Naval Medicine and for the maintenance of the Navy in the leadership of the Underwater and Hyperbaric Medicine (UHM) practice in our country, which does not surprise, since the medical aspects related with the dive and with the exposure to changes of the ambient pressure are specificities of the Naval Medicine, and that the CUHM's main mission is to ensure the maintenance of the efficacy of the forces involved in the practice of such operational activities.

Keywords: hyperbaric; medicine; naval; underwater Prehosp Disast Med 2010;25(5):s103

\section{Psychological Resilience}

Psychological Support for Mental Health in Times of Crisis within a Strategy for Lifelong Learning

Vivienne Soykova

1st Medical Faculty, Charles University in Prague, Faculty of

Transportation Sciences, CTU, Prague, Czech Republic

Introduction: Special emphasis is placed on crisis preparedness procedures for psychological support for mental health. The frame is taken from social-psycho-pedagogical approaches. The support procedures must be focused on training to ensure the professionals as well as the volunteers are fully ready to "decontaminate stress" in time of crisis interventions.

Methods: Training using a simulation model is very important in the framework of preparedness, and fits-in-well with the systematic approaches adopted in the framework as EU documents and National Lifelong Learning programs. The concepts of Lifelong Education and Lifelong Counseling (EU) emphasize long-term preparation. These approaches take into account pedagogical psychology (philosophy and psychology of learning), demographic, and social considerations, as well as "psychology of stress". The concept of Lifelong Learning developed by international organizations (EC, UNESCO, OECD, etc.) concentrated on social and cultural development through "new ways of humanism", while work approaches only were touched on.

Harmonious international collaboration is essential in the sphere, and all major stakeholders should be involved: representatives of employees, employers, educationists, state and local authorities, all working together with professionals in each phase. The program is based on the ideas expressed in Education and Training 2010-the Success of the Lisbon Strategy. Psychological Support for Mental Health is a detail, but essentially important as a pillar of the program.

Results Expected: The best effects always are started by good and effective educational approaches, and they are improved by "best practices".

Conclusions: NATO can be a good source of expert advice on education for the sphere of crisis preparedness for the EU nations (source of international "good practices"). The NATO document, as non-binding recommendation, could be a good base. Such an international document is expected by crisis preparedness professionals to be a real support for educational approaches with training.

Keywords: crisis; preparedness; learning; mental health; preparedness; psychosocial; stress Prehosp Disast Med 2010;25(5):s103 